\title{
Yelena Mazour-Matusevich, La position de Gerson (1363-1429) envers les femmes
}

\section{Paola Cifarelli}

\section{Q OpenEdition}

1 Journals

\section{Edizione digitale}

URL: http://journals.openedition.org/studifrancesi/9791

DOI: 10.4000/studifrancesi.9791

ISSN: 2421-5856

\section{Editore}

Rosenberg \& Sellier

\section{Edizione cartacea}

Data di pubblicazione: 1 octobre 2007

Paginazione: 419

ISSN: 0039-2944

\section{Notizia bibliografica digitale}

Paola Cifarelli, «Yelena Mazour-Matusevich, La position de Gerson (1363-1429) envers les femmes», Studi Francesi [Online], 152 (LI | II) | 2007, online dal 30 novembre 2015, consultato il 09 janvier 2021. URL: http://journals.openedition.org/studifrancesi/9791 ; DOI: https://doi.org/10.4000/studifrancesi.9791

Questo documento è stato generato automaticamente il 9 janvier 2021.

\section{(c) $(1) \&$}

Studi Francesi è distribuita con Licenza Creative Commons Attribuzione - Non commerciale - Non opere derivate 4.0 Internazionale. 


\title{
Yelena Mazour-Matusevich, La position de Gerson (1363-1429) envers les femmes
}

\author{
Paola Cifarelli
}

\section{NOTIZIA}

YeLENA MAZOUR-MATUSEVICH, La position de Gerson (1363-1429) envers les femmes, «Le Moyen Âge», CXII, n. 2, 2006, pp. 337-353.

1 Tornando su un problema molto spesso dibattuto dalla critica, l'A. esamina questo tema non tanto in rapporto con l'atteggiamento di Gerson verso le donne 'mistiche', quanto piuttosto inserendolo nel contesto delle sue idee a proposito dei bambini, della famiglia e delle relazioni coniugali. Nei due trattati in francese destinati a divulgare i principi della vita spirituale (la Montagne de contemplation e La Mendicité spirituelle), oltre che sull'Adventica et Respectus habendi ad injunctionem penitientie publice, recentemente edito da G. Ouy (cf. questi «Studi», n. 139, 2003, p. 138) il cancelliere mostra un eccezionale rispetto verso la donna, a cui riconosce dignità, pietà e soprattutto la virtù dell'umiltà, e per cui auspica maggiore indulgenza e rispetto da parte del coniuge, della società $\mathrm{e}$ della giustizia. 